\title{
Coupled coincidence point theorems for compatible mappings in partially ordered intuitionistic generalized fuzzy metric spaces
}

\author{
Syed Abdul Mohiuddine and Abdullah Alotaibi*
}

"Correspondence:

mathker11@hotmail.com Department of Mathematics,

Faculty of Science, King Abdulaziz University, P.O. Box 80203, Jeddah,

21589, Saudi Arabia

\begin{abstract}
In this work, we introduce the notion of intuitionistic generalized fuzzy metric space by using the idea of intuitionistic fuzzy set due to Atanassov. We determine some coupled coincidence point results for compatibility of two mappings, that is, $F: X \times X \rightarrow X$ and $g: X \rightarrow X$, in the framework of intuitionistic generalized fuzzy metric spaces endowed with partial order. An interesting example is also displayed here in support of our result.
\end{abstract}

Keywords: $t$-norm; $t$-conorm; coupled coincidence point; compatible mappings; generalized metric space

\section{Preliminaries, background and notation}

Zadeh [1] suggests the creation of what are called fuzzy sets which base their development on the idea that the membership of an element to a set is indicated by a number between 0 and 1 , having non-membership for 0 , membership for 1 and different degrees of membership for the numbers between 0 and 1 . Such sets have proved very useful in the description of phenomena governed by imprecise parameters as well as for the development of non-bivalent logic models. Using the idea of fuzzy set, many authors have introduced the concept of fuzzy metric in different point of views [2-4]. George and Veeramani [5] modified the concept of fuzzy metric space due to Kramosil and Michalek [4].

Atanassov [6] suggests a generalization of fuzzy sets making the degrees of membership and non-membership intervene to describe the vinculation of an element to a set, so that the sum of these degrees is always less or equal to 1 , that is, an intuitionistic fuzzy set. Park [7] introduced and discussed the concept of intuitionistic fuzzy metric space which is based on the idea of intuitionistic fuzzy set and the notion of fuzzy metric space given by George and Veeramani [5]. Afterward, it was followed by the notion of intuitionistic fuzzy normed space and intuitionistic fuzzy bounded linear operators [8-18]. The authors of [19-21] established an interesting relationship between three various disciplines: the theory of fuzzy normed spaces, the theory of stability of functional equations and fixed point theory.

The concept of generalized metric space was introduced and studied by Mustafa and Sims [22] and was later used to determine coupled fixed point theorems and related results by a number of authors [23-33]. Sun and Yang [34] defined the notion of generalized fuzzy

\section{䈝 Springer}

(O2013 Mohiuddine and Alotaibi; licensee Springer. This is an Open Access article distributed under the terms of the Creative Commons Attribution License (http://creativecommons.org/licenses/by/2.0), which permits unrestricted use, distribution, and reproduction in any medium, provided the original work is properly cited. 
metric space with the help of generalized metric space and fuzzy sets, and further studied it in $[35,36]$ to deal with some fixed point theory.

In this work, we present an interesting generalization of generalized fuzzy metric space with the help of an intuitionistic fuzzy set and call it an intuitionistic generalized fuzzy metric space. We also define the notions of convergence, Cauchy sequences and compatibility of two mappings in this setup. Further, we establish coupled coincidence point and coupled fixed point results for compatible mappings in partially ordered intuitionistic generalized fuzzy metric spaces and construct an example in support of our result.

Now, we recall some definitions and notations which we will used throughout the article. We shall assume throughout this paper that the symbols $\mathbb{R}$ and $\mathbb{N}$ denote the set of real and natural numbers, respectively. In this section, we recall some definitions and preliminary results which we will use throughout the paper. Mustafa and Sims [22] defined the notion of generalized metric space as follows.

Let $X$ be a nonempty set and a mapping $\mathcal{G}: X \times X \times X \rightarrow \mathbb{R}$. Then $\mathcal{G}$ is called a generalized metric (for short, $\mathcal{G}$-metric) on $X$ and $(X, \mathcal{G})$ a generalized metric space or simply a $\mathcal{G}$-metric space if the following conditions are satisfied:

(i) $\mathcal{G}(x, y, z)=0$ if $x=y=z$,

(ii) $\mathcal{G}(x, x, y)>0$ for all $x, y \in X$ and $x \neq y$,

(iii) $\mathcal{G}(x, x, y) \leq \mathcal{G}(x, y, z)$ for all $x, y, z \in X$ and $y \neq z$,

(iv) $\mathcal{G}(x, y, z)=\mathcal{G}(x, z, y)=\mathcal{G}(y, z, x)=\cdots$ (symmetry in all three variables),

(v) $\mathcal{G}(x, y, z) \leq \mathcal{G}(x, a, a)+\mathcal{G}(a, y, z)$ for all $x, y, z, a \in X$ (rectangle inequality).

We remark that every $\mathcal{G}$-metric on $X$ defines a metric $d_{\mathcal{G}}$ on $X$ by $d_{\mathcal{G}}(x, y)=\mathcal{G}(x, y, y)+$ $\mathcal{G}(y, x, x)$ for all $x, y \in X$.

For example, let $(X, d)$ be a metric space. The function $\mathcal{G}: X \times X \times X \rightarrow[0, \infty)$ is defined by

$$
\mathcal{G}(x, y, z)=\max \{d(x, y), d(y, z), d(z, x)\}
$$

or

$$
\mathcal{G}(x, y, z)=d(x, y)+d(y, z)+d(z, x)
$$

for all $x, y, z \in X$. Then $(X, \mathcal{G})$ is a $\mathcal{G}$-metric space [22].

Bhaskar and Lakshmikantham [37] presented the definitions of mixed monotone property and coupled fixed point for the contractive mapping $F: X \times X \rightarrow X$ and established some coupled fixed point theorems for a mixed monotone operator. As an application of the coupled fixed point theorems, they determined the existence and uniqueness of the solution of a periodic boundary value problem. Afterward, Lakshmikantham and Cirić [38] presented the notions of mixed $g$-monotone property and coupled coincidence point and proved coupled coincidence and coupled common fixed point theorems for nonlinear contractive mappings in partially ordered complete metric spaces. Many authors obtained important fixed point theorems, for details and background of fixed point theory, we refer to [39-48] and references therein.

Definition 1.1 [37] Let $(X, \leq)$ be a partially ordered set and $F: X \times X \rightarrow X$ be a mapping. Then a map $F$ is said to have the mixed monotone property if $F(x, y)$ is monotone non- 
decreasing in $x$ and is monotone non-increasing in $y$; that is, for any $x, y \in X$,

$$
x_{1}, x_{2} \in X, \quad x_{1} \leq x_{2} \quad \text { implies } \quad F\left(x_{1}, y\right) \leq F\left(x_{2}, y\right)
$$

and

$$
y_{1}, y_{2} \in X, \quad y_{1} \leq y_{2} \quad \text { implies } \quad F\left(x, y_{1}\right) \geq F\left(x, y_{2}\right) .
$$

Definition 1.2 [37] An element $(x, y) \in X \times X$ is said to be a coupled fixed point of the mapping $F: X \times X \rightarrow X$ if

$$
F(x, y)=x \quad \text { and } \quad F(y, x)=y .
$$

Definition 1.3 [38] Let $(X, \leq)$ be a partially ordered set, and let $F: X \times X \rightarrow X$ and $g$ : $X \rightarrow X$ be two mappings. Then a map $F$ is said to have the mixed $g$-monotone property if $F$ is monotone $g$-non-decreasing in its first argument and is monotone $g$-non-increasing in its second argument, that is, for any $x, y \in X$,

$$
x_{1}, x_{2} \in X, \quad g\left(x_{1}\right) \leq g\left(x_{2}\right) \quad \text { implies } \quad F\left(x_{1}, y\right) \leq F\left(x_{2}, y\right)
$$

and

$$
y_{1}, y_{2} \in X, \quad g\left(y_{1}\right) \leq g\left(y_{2}\right) \quad \text { implies } \quad F\left(x, y_{1}\right) \geq F\left(x, y_{2}\right) .
$$

Definition 1.4 [38] An element $(x, y) \in X \times X$ is said to be a coupled coincidence point of mappings $F: X \times X \rightarrow X$ and $g: X \rightarrow X$ if

$$
F(x, y)=g x \quad \text { and } \quad F(y, x)=g y .
$$

Definition 1.5 [38] Let $X$ be a nonempty set, and let $F: X \times X \rightarrow X$ and $g: X \rightarrow X$ be two mappings. Then $F$ and $g$ are commutative if for all $x, y, z \in X$, we have

$$
g(F(x, y))=F(g x, g y) .
$$

Definition 1.6 [41] Let $(X, d)$ be an IGFM-space. The mappings $F$ and $g$, where $F: X \times$ $X \rightarrow X$ and $g: X \rightarrow X$, are said to be compatible if

$$
\lim _{n \rightarrow \infty} d\left(g\left(F\left(x_{n}, y_{n}\right)\right), F\left(g\left(x_{n}\right), g\left(y_{n}\right)\right), t\right)=0
$$

and

$$
\lim _{n \rightarrow \infty} d\left(g\left(F\left(y_{n}, x_{n}\right)\right), F\left(g\left(y_{n}\right), g\left(x_{n}\right)\right), t\right)=0,
$$

whenever $\left(x_{n}\right)$ and $\left(y_{n}\right)$ are sequences in $X$ such that $\lim _{n \rightarrow \infty} F\left(x_{n}, y_{n}\right)=\lim _{n \rightarrow \infty} g\left(x_{n}\right)=x$ and $\lim _{n \rightarrow \infty} F\left(y_{n}, x_{n}\right)=\lim _{n \rightarrow \infty} g\left(y_{n}\right)=y$ for some $x, y \in X$.

Afterward, the concept of compatible mappings was introduced in fuzzy metric spaces by $\mathrm{Hu}$ [49]. In the recent past, $\mathrm{Hu}$ and Luo [36] defined and studied this notion in the framework of generalized fuzzy metric spaces. 


\section{Intuitionistic generalized fuzzy metric space}

Let us recall [50] that a binary operation $*:[0,1] \times[0,1] \rightarrow[0,1]$ is said to be a continuous $t$-norm if it satisfies the following conditions:

(a) $*$ is associative and commutative,

(b) $*$ is continuous,

(c) $a * 1=a$ for all $a \in[0,1]$,

(d) $a * b \leq c * d$ whenever $a \leq c$ and $b \leq d$ for each $a, b, c, d \in[0,1]$.

Similarly, a binary operation $\diamond:[0,1] \times[0,1] \rightarrow[0,1]$ is said to be a continuous $t$-conorm if it satisfies the following conditions:

$\left(a^{\prime}\right) \diamond$ is associative and commutative,

$\left(\mathrm{b}^{\prime}\right) \diamond$ is continuous,

(c') $a \diamond 0=a$ for all $a \in[0,1]$,

(d') $a \diamond b \leq c \diamond d$ whenever $a \leq c$ and $b \leq d$ for each $a, b, c, d \in[0,1]$.

Remark 2.1 The concepts of triangular norms (t-norms) and triangular conorms $(t$ conorms) are known as the axiomatic skeletons that we use for characterizing fuzzy intersections and unions, respectively.

In 2004, Park [7] presented the notion of intuitionistic fuzzy metric space as follows: The 5-tuple $X, M, N, * \diamond \diamond$ is said to be an intuitionistic fuzzy metric space if $X$ is an arbitrary set, $*$ is a continuous $t$-norm, $\diamond$ is a continuous $t$-conorm and $M, N$ are fuzzy sets on $X^{2} \times(0, \infty)$ satisfying the following conditions for all $x, y, z \in X, s, t>0$ : (i) $M(x, y, t)+$ $N(x, y, t) \leq 1$, (ii) $M(x, y, t)>0$, (iii) $M(x, y, t)=1$ if and only if $x=y$, (iv) $M(x, y, t)=$ $M(y, x, t)$, (v) $M(x, y, t) * M(y, z, t) \leq M(x, z, t+s)$, (vi) $M(x, y, \cdot):(0, \infty) \rightarrow(0,1]$ is continuous, (vii) $N(x, y, t)<1$, (viii) $N(x, y, t)=0$ if and only if $x=y$, (ix) $N(x, y, t)=N(y, x, t)$, (x) $N(x, y, t) \diamond N(y, z, s) \geq N(x, z, t+s)$, and $(\mathrm{xi}) N(x, y, \cdot):(0, \infty) \rightarrow(0,1]$ is continuous.

Now, we introduce the notion of intuitionistic generalized fuzzy metric space by using the concepts of continuous $t$-norm and $t$-conorm.

Definition 2.2 The 5-tuple $(X, G, H, *, \diamond)$ is said to be an intuitionistic generalized fuzzy metric space (for short, IGFM-space) if $X$ is an arbitrary nonempty set, $*$ is a continuous $t$-norm, $\diamond$ is a continuous $t$-conorm, and $G, H$ are fuzzy sets on $X^{3} \times(0, \infty)$ satisfying the following conditions. For every $x, y, z, a \in X$ and $s, t>0$,

(i) $G(x, y, z, t)+H(x, y, z, t) \leq 1$,

(ii) $G(x, x, y, t)>0$ for $x \neq y$,

(iii) $G(x, x, y, t) \geq G(x, y, z, t)$ for $y \neq z$,

(iv) $G(x, y, z, t)=1$ if and only if $x=y=z$,

(v) $G(x, y, z, t)=G(p(x, y, z), t)$, where $p$ is a permutation function,

(vi) $G(x, a, a, t) * G(a, y, z, s) \leq G(x, y, z, t+s)$,

(vii) $G(x, y, z, \cdot):(0, \infty) \rightarrow[0,1]$ is continuous,

(viii) $G$ is a non-decreasing function on $\mathbb{R}^{+}$,

$$
\lim _{t \rightarrow \infty} G(x, y, z, t)=1, \quad \lim _{t \rightarrow 0} G(x, y, z, t)=0, \quad \forall x, y, z \in X, t>0,
$$

(xi) $H(x, x, y, t)<1$ for $x \neq y$,

(x) $H(x, x, y, t) \leq H(x, y, z, t)$ for $y \neq z$, 
(xi) $H(x, y, z, t)=0$ if and only if $x=y=z$,

(xii) $H(x, y, z, t)=H(p(x, y, z), t)$, where $p$ is a permutation function,

(xiii) $H(x, a, a, t) \diamond H(a, y, z, s) \geq H(x, y, z, t+s)$,

(xiv) $H(x, y, z, \cdot):(0, \infty) \rightarrow[0,1]$ is continuous,

(xv) $H$ is a non-increasing function on $\mathbb{R}^{+}$,

$$
\lim _{t \rightarrow \infty} H(x, y, z, t)=0, \quad \lim _{t \rightarrow 0} H(x, y, z, t)=1 \quad \forall x, y, z \in X, t>0 .
$$

In this case, the pair $(G, H)$ is called an intuitionistic generalized fuzzy metric on $X$.

Example 2.3 Let $(X, \mathcal{G})$ be a $\mathcal{G}$-metric space. For all $x, y, z \in X$ and every $t>0$, consider $G$, $H$ to be fuzzy sets on $X^{3} \times(0, \infty)$ defined by

$$
G(x, y, z, t)=\frac{t}{t+\mathcal{G}(x, y, z)} \quad \text { and } \quad H(x, y, z, t)=\frac{\mathcal{G}(x, y, z)}{t+\mathcal{G}(x, y, z)}
$$

and denote

$$
a * b=a b \quad \text { and } \quad a \diamond b=\min \{a+b, 1\} \quad(a, b \in[0,1]) \text {. }
$$

Then $(X, G, H, *, \diamond)$ is an intuitionistic generalized fuzzy metric space. Notice that the above example holds even with the $t$-norm $a * b=\min (a, b)$ and the $t$-conorm $a \diamond b=$ $\max (a, b)$. We remark that this intuitionistic generalized fuzzy metric is induced by a $\mathcal{G}$-metric $\mathcal{G}$, the standard intuitionistic generalized fuzzy metric.

Remark 2.4 In an intuitionistic generalized fuzzy metric space, $G(x, y, z, \cdot)$ is nondecreasing and $H(x, y, z, \cdot)$ is non-increasing for all $x, y, z \in X$.

Definition 2.5 Let $x \in X$, where $(X, G, H, *, \diamond)$ is an IGFM-space. Then, for $r \in(0,1)$ and $t>0$, the set

$$
B_{G, H}(x, r, t)=\{y \in X: G(x, y, y, t)>1-r \text { and } H(x, y, y, t)<r\}
$$

is said to be an open ball with center $x$ and radius $r$ with respect to $t$. Note that every open ball $B_{G, H}(x, r, t)$ is an open set.

Remark 2.6 Let $(X, G, H, *, \diamond)$ be an IGFM-space. Define $\tau_{G, H}=\{A \subset X$ : for each $x \in$ $A$, there exist $t>0$ and $r \in(0,1)$ such that $\left.B_{G, H}(x, r, t) \subset A\right\}$. Then $\tau_{G, H}$ is a topology on $X$ (induced by the intuitionistic generalized fuzzy metric $(G, H)$ ).

Recall that a topological space is first countable if each point has a countable (decreasing) local base. Since $B_{G, H}(x, 1 / n, 1 / n)$ is a local base at $x$, then topology $\tau_{G, H}$ is first countable.

Definition 2.7 Let $(X, G, H, *, \diamond)$ be an IGFM-space. Then a sequence $\left(x_{j}\right)$ is said to be convergent to $x \in X$ with respect to the intuitionistic generalized fuzzy metric $(G, H)$ if for every $\epsilon>0$ and $t>0$, there exists $j_{0} \in \mathbb{N}$ such that $G\left(x_{j}, x_{k}, x, t\right)>1-\epsilon$ and $H\left(x_{j}, x_{k}, x, t\right)<\epsilon$ for all $j, k \geq j_{0}$. In this case, we write $x_{j} \stackrel{(G, H)}{\longrightarrow} x$ or $(G, H)-\lim x_{j}=x$. 
Theorem 2.8 Let $(X, G, H, *, \diamond)$ be an IGFM-space and $\tau_{G, H}$ be the topology induced by the fuzzy metric. Then, for a sequence $\left(x_{j}\right)$ in $X, x_{j} \stackrel{(G, H)}{\longrightarrow} x$ if and only if $G\left(x_{j}, x_{j}, x, t\right) \rightarrow 1$ and $H\left(x_{j}, x_{j}, x, t\right) \rightarrow 0$ as $j \rightarrow \infty$.

Proof Let $\left(x_{j}\right)$ be convergent to $x$ with respect to an intuitionistic generalized fuzzy metric $(G, H)$, i.e., $x_{j} \stackrel{(G, H)}{\longrightarrow} x$. Then, for every $r \in(0,1)$ and $t>0$, there is a number $j_{0} \in \mathbb{N}$ such that $x_{j} \in B_{G, H}(x, r, t)$ for all $j \geq j_{0}$. It follows that $G\left(x_{j}, x_{j}, x, t\right)>1-r$ and $H\left(x_{j}, x_{j}, x, t\right)<r$ and hence $1-G\left(x_{j}, x_{j}, x, t\right)<r$ and $H\left(x_{j}, x_{j}, x, t\right)<r$. Thus, $G\left(x_{j}, x_{j}, x, t\right) \rightarrow 1$ and $H\left(x_{j}, x_{j}, x, t\right) \rightarrow 0$ as $j \rightarrow \infty$.

Conversely, suppose that $G\left(x_{j}, x_{j}, x, t\right) \rightarrow 1$ and $H\left(x_{j}, x_{j}, x, t\right) \rightarrow 0$ as $j \rightarrow \infty$ for each $t>0$. Then, for any $t>0$ and $r \in(0,1)$, there exists $j_{0} \in \mathbb{N}$ such that $1-G\left(x_{j}, x_{j}, x, t\right)<r$ and $H\left(x_{j}, x_{j}, x, t\right)<r$ for all $j \geq j_{0}$. It follows that $G\left(x_{j}, x_{j}, x, t\right)>1-r$ and $H\left(x_{j}, x_{j}, x, t\right)<r$ for all $j \geq j_{0}$. Therefore $x_{j} \in B_{G, H}(x, r, t)$ for all $j \geq j_{0}$. Hence $\left(x_{j}\right)$ is convergent to $x$ with respect to $(G, H)$.

Definition 2.9 Let $(X, G, H, *, \diamond)$ be an IGFM-space. Then $\left(x_{j}\right)$ is a Cauchy sequence with respect to the intuitionistic generalized fuzzy metric $(G, H)$ if, for every $\epsilon>0$ and $t>0$, there exists $j_{0} \in \mathbb{N}$ such that $G\left(x_{j}, x_{\ell}, x_{k}, t\right)>1-\epsilon$ and $H\left(x_{j}, x_{\ell}, x_{k}, t\right)<\epsilon$ for all $j, \ell, k \geq j_{0}$. An IGFM-space $(X, G, H, *, \diamond)$ is said to be complete if every Cauchy sequence with respect to the intuitionistic generalized fuzzy metric $(G, H)$ is convergent with respect to $(G, H)$.

\section{Coupled coincidence results for compatible mappings}

In this section we establish coupled coincidence theorems for compatibility of two mappings in partially ordered intuitionistic generalized fuzzy metric spaces. Before proceeding further, first we define the notion of compatible mappings with respect to the intuitionistic generalized fuzzy metric $(G, H)$ as follows.

Definition 3.1 Let $(X, G, H, *, \diamond)$ be an IGFM-space. The mappings $F$ and $g$, where $F$ : $X \times X \rightarrow X$ and $g: X \rightarrow X$, are said to be compatible with respect to $(G, H)$ if for all $t>0$,

$$
\begin{aligned}
& \lim _{n \rightarrow \infty} G\left(g\left(F\left(x_{n}, y_{n}\right)\right), g\left(F\left(x_{n}, y_{n}\right)\right), F\left(g\left(x_{n}\right), g\left(y_{n}\right)\right), t\right)=1, \\
& \lim _{n \rightarrow \infty} H\left(g\left(F\left(x_{n}, y_{n}\right)\right), g\left(F\left(x_{n}, y_{n}\right)\right), F\left(g\left(x_{n}\right), g\left(y_{n}\right)\right), t\right)=0
\end{aligned}
$$

and

$$
\begin{aligned}
& \lim _{n \rightarrow \infty} G\left(g\left(F\left(y_{n}, x_{n}\right)\right), g\left(F\left(y_{n}, x_{n}\right)\right), F\left(g\left(y_{n}\right), g\left(x_{n}\right)\right), t\right)=1, \\
& \lim _{n \rightarrow \infty} H\left(g\left(F\left(y_{n}, x_{n}\right)\right), g\left(F\left(y_{n}, x_{n}\right)\right), F\left(g\left(y_{n}\right), g\left(x_{n}\right)\right), t\right)=0,
\end{aligned}
$$

whenever $\left(x_{n}\right)$ and $\left(y_{n}\right)$ are sequences in $X$ such that $\lim _{n \rightarrow \infty} F\left(x_{n}, y_{n}\right)=\lim _{n \rightarrow \infty} g\left(x_{n}\right)=x$ and $\lim _{n \rightarrow \infty} F\left(y_{n}, x_{n}\right)=\lim _{n \rightarrow \infty} g\left(y_{n}\right)=y$ for some $x, y \in X$.

Secondly, we prove the following lemmas which we will used to prove our coupled coincidence theorem. 
Lemma 3.2 Let $(X, G, H, *, \diamond)$ be an IGFM-space. Suppose that $\Im_{\lambda}: X^{3} \rightarrow[0, \infty)$ is defined by

$$
\Im_{\lambda}(x, y, z)=\inf \{t>0: G(x, y, z, t)>1-\lambda \text { and } H(x, y, z, t)<\lambda\}
$$

for all $x, y, z \in X, \lambda \in(0,1]$ and $t>0$. Then, for each $\lambda \in(0,1]$, there exists $\mu \in(0,1]$ such that

$$
\Im_{\lambda}\left(x_{1}, x_{1}, x_{n}\right) \leq \sum_{j=1}^{n-1} \Im_{\mu}\left(x_{j}, x_{j}, x_{j+1}\right)
$$

for all $x_{1}, x_{2}, \ldots, x_{n} \in X$.

Proof Given $\lambda \in(0,1]$ choose $\mu \in(0,1]$ such that $(1-\mu) *(1-\mu) * \cdots *(1-\mu)>1-\lambda$ and $\mu \diamond \mu \diamond \cdots \diamond \mu<\lambda$. Then, for any $\epsilon>0$, write

$$
\begin{aligned}
& G\left(x_{1}, x_{1}, x_{n}, \sum_{j=1}^{n-1} \mathfrak{\Im}_{\mu}\left(x_{j}, x_{j}, x_{j+1}\right)+(\overbrace{\epsilon+\cdots+\epsilon}^{(n-1) \text { times }})\right) \\
& \geq G\left(x_{1}, x_{1}, x_{2}, \Im_{\mu}\left(x_{1}, x_{1}, x_{2}\right)+\epsilon\right) * G\left(x_{2}, x_{2}, x_{3}, \Im_{\mu}\left(x_{2}, x_{2}, x_{3}\right)+\epsilon\right) * \cdots \\
& \quad * G\left(x_{n-1}, x_{n-1}, x_{n}, \Im_{\mu}\left(x_{n-1}, x_{n-1}, x_{n}\right)+\epsilon\right) \\
& >(1-\mu) *(1-\mu) * \cdots *(1-\mu)>1-\lambda
\end{aligned}
$$

and, similarly,

$$
\begin{aligned}
& H\left(x_{1}, x_{1}, x_{n}, \sum_{j=1}^{n-1} \mathfrak{\Im}_{\mu}\left(x_{j}, x_{j}, x_{j+1}\right)+(\overbrace{\epsilon+\cdots+\epsilon}^{(n-1) \text { times }})\right) \\
& \leq H\left(x_{1}, x_{1}, x_{2}, \mathfrak{\Im}_{\mu}\left(x_{1}, x_{1}, x_{2}\right)+\epsilon\right) \diamond G\left(x_{2}, x_{2}, x_{3}, \Im_{\mu}\left(x_{2}, x_{2}, x_{3}\right)+\epsilon\right) \diamond \cdots \\
& \quad \diamond H\left(x_{n-1}, x_{n-1}, x_{n}, \Im_{\mu}\left(x_{n-1}, x_{n-1}, x_{n}\right)+\epsilon\right) \\
& <\mu \diamond \mu \diamond \cdots \diamond \mu<\lambda .
\end{aligned}
$$

This implies

$$
\begin{aligned}
\mathfrak{\Im}_{\lambda}\left(x_{1}, x_{1}, x_{n}\right) \leq & \Im_{\mu}\left(x_{1}, x_{1}, x_{2}\right)+\mathfrak{I}_{\mu}\left(x_{2}, x_{2}, x_{3}\right)+\cdots \\
& +\mathfrak{I}_{\mu}\left(x_{n-1}, x_{n-1}, x_{n}\right)+(n-1) \epsilon .
\end{aligned}
$$

Since $\epsilon>0$ was arbitrary, we have

$$
\mathfrak{\Im}_{\lambda}\left(x_{1}, x_{1}, x_{n}\right) \leq \mathfrak{I}_{\mu}\left(x_{1}, x_{1}, x_{2}\right)+\mathfrak{\Im}_{\mu}\left(x_{2}, x_{2}, x_{3}\right)+\cdots+\mathfrak{\Im}_{\mu}\left(x_{n-1}, x_{n-1}, x_{n}\right) .
$$

Denote by $\Phi$ the family of strictly increasing functions $\phi:[0,+\infty) \rightarrow[0,+\infty)$ such that $\sum_{n=1}^{\infty} \phi^{n}(t)<\infty$ for all $t>0$, where $\phi^{n}$ is the $n$th iterate of $\phi$ and satisfies (i) $\psi$ is upper semi-continuous, (ii) $\phi^{-1}(\{0\})=\{0\}$, (iii) $\phi(t)<t$ for all $t>0$. 
Lemma 3.3 Let $(X, G, H, *, \diamond)$ be an IGFM-space and $\left(y_{n}\right)$ be a sequence in X. Suppose that there exists $\phi \in \Phi$ such that

$$
\left.\begin{array}{l}
G\left(y_{n}, y_{n}, y_{n+1}, \phi(t)\right) \geq G\left(y_{n-1}, y_{n-1}, y_{n}, t\right) * G\left(y_{n}, y_{n}, y_{n+1}, t\right) \quad \text { and } \\
H\left(y_{n}, y_{n}, y_{n+1}, \phi(t)\right) \leq H\left(y_{n-1}, y_{n-1}, y_{n}, t\right) \diamond H\left(y_{n}, y_{n}, y_{n+1}, t\right)
\end{array}\right\}
$$

for all $t>0$. Then $\left(y_{n}\right)$ is a Cauchy sequence with respect to the intuitionistic generalized fuzzy metric $(G, H)$.

Proof Let $\mathfrak{\Im}_{\lambda}(x, y, z)$ be given by (3.1). For simplicity in notation, write $a_{n}=\Im_{\lambda}\left(y_{n-1}, y_{n-1}, y_{n}\right)$ for each $\lambda \in(0,1]$. We have to show that

$$
a_{n+1} \leq \phi\left(a_{n}\right) \quad \text { for all } n \in \mathbb{N} \text {. }
$$

Since $\phi$ is upper semi-continuous from right, for given $\epsilon>0$ and each $a_{n}$, there exists $p_{n}>a_{n}$ such that $\phi\left(p_{n}\right)<\phi\left(a_{n}\right)+\epsilon$. It follows from (3.1) that

$$
G\left(y_{n-1}, y_{n-1}, y_{n}, p_{n}\right)>1-\lambda \text { and } H\left(y_{n-1}, y_{n-1}, y_{n}, p_{n}\right)<\lambda \text {. }
$$

From (3.2), we have

$$
\begin{aligned}
& G\left(y_{n}, y_{n}, y_{n+1}, \phi\left(\max \left\{p_{n}, p_{n+1}\right\}\right)\right) \\
& \quad \geq G\left(y_{n-1}, y_{n-1}, y_{n}, \max \left\{p_{n}, p_{n+1}\right\}\right) * G\left(y_{n}, y_{n}, y_{n+1}, \max \left\{p_{n}, p_{n+1}\right\}\right) \\
& \quad \geq G\left(y_{n-1}, y_{n-1}, y_{n}, p_{n}\right) * G\left(y_{n}, y_{n}, y_{n+1}, p_{n+1}\right)>1-\lambda
\end{aligned}
$$

and

$$
\begin{aligned}
& H\left(y_{n}, y_{n}, y_{n+1}, \phi\left(\max \left\{p_{n}, p_{n+1}\right\}\right)\right) \\
& \quad \leq H\left(y_{n-1}, y_{n-1}, y_{n}, \max \left\{p_{n}, p_{n+1}\right\}\right) \diamond H\left(y_{n}, y_{n}, y_{n+1}, \max \left\{p_{n}, p_{n+1}\right\}\right) \\
& \quad \leq H\left(y_{n-1}, y_{n-1}, y_{n}, p_{n}\right) \diamond H\left(y_{n}, y_{n}, y_{n+1}, p_{n+1}\right)<\lambda .
\end{aligned}
$$

Again, from (3.1), we have

$$
\Im_{\lambda}\left(y_{n}, y_{n}, y_{n+1}\right) \leq \phi\left(\max \left\{p_{n}, p_{n+1}\right\}\right)=\max \left\{\phi\left(p_{n}\right), \phi\left(p_{n+1}\right)\right\} \leq \max \left\{\phi\left(a_{n}\right), \phi\left(a_{n+1}\right)\right\}+\epsilon .
$$

Since $\epsilon>0$ was arbitrary, we have

$$
a_{n+1}=\Im_{\lambda}\left(y_{n}, y_{n}, y_{n+1}\right) \leq \max \left\{\phi\left(a_{n}\right), \phi\left(a_{n+1}\right)\right\} .
$$

Then $a_{n+1} \leq \phi\left(a_{n}\right)$. Otherwise, $a_{n+1} \leq \phi\left(a_{n+1}\right)<a_{n+1}$ which is not possible. Proceeding along the same lines as in the proof of Lemma 2.5 in [36], for a given $\epsilon>0$, there exists $n_{0} \in \mathbb{N}$ such that

$$
G\left(y_{n}, y_{n}, y_{m}, \epsilon\right)>1-\lambda \text { and } H\left(y_{n}, y_{n}, y_{m}, \epsilon\right)<\lambda
$$

for all $m, n \geq n_{0}$. Hence $\left(y_{n}\right)$ is a Cauchy sequence with respect to the intuitionistic generalized fuzzy metric $(G, H)$. 
Now, we are ready to determine a coupled coincidence theorem for compatible mappings in partially ordered intuitionistic generalized fuzzy metric spaces.

Theorem 3.4 Let $(X, \leq)$ be a partially ordered set and $(X, G, H, *, \diamond)$ be a complete IGFMspace. Suppose that $F: X \times X \rightarrow X$ and $g: X \rightarrow X$ are mappings such that $F$ has the mixed $g$-monotone property, and also assume that there exists $\phi \in \Phi$ such that

$$
\left.\begin{array}{rl}
G(F(x, y), F(x, y), F(u, v), \phi(t)) \geq & G(g(x), g(x), u, t) * G(g(x), g(x), F(x, y), t) \\
& * G(g(u), g(u), F(u, v), t) \\
\text { and } & \\
H(F(x, y), F(x, y), F(u, v), \phi(t)) \leq & H(g(x), g(x), u, t) \diamond H(g(x), g(x), F(x, y), t) \\
& \diamond H(g(u), g(u), F(u, v), t)
\end{array}\right\}
$$

for all $x, y, u, v \in X$ and $t>0$ with $g(x) \leq g(u)$ and $g(y) \geq g(v)$, or $g(x) \geq g(u)$ and $g(y) \leq g(v)$. Suppose that $F(X \times X) \subseteq g(X), g$ is continuous and $F$ and $g$ are compatible with respect to $(G, H)$, and also suppose that either

(a) $F$ is continuous, or

(b) $X$ has the following property:

(i) if a non-decreasing sequence $x_{n}$ is convergent to $x$ with respect to $(G, H)$, then $x_{n} \leq x$ for all $n$,

(ii) if a non-increasing sequence $y_{n}$ is convergent to $y$ with respect to $(G, H)$, then $y_{n} \geq y$ for all $n$.

If there exist $x_{0}, y_{0} \in X$ with $g\left(x_{0}\right) \leq F\left(x_{0}, y_{0}\right)$ and $g\left(y_{0}\right) \geq F\left(y_{0}, x_{0}\right)$, then there exist $x, y \in X$ such that $g(x)=F(x, y)$ and $g(y)=F(y, x)$; that is, $F$ and $g$ have a coupled coincidence point.

Proof Let $x_{0}, y_{0} \in X$ be such that $g\left(x_{0}\right) \leq F\left(x_{0}, y_{0}\right)$ and $g\left(y_{0}\right) \geq F\left(y_{0}, x_{0}\right)$. Since $F(X \times X) \subseteq$ $g(X)$, we can choose $x_{1}, y_{1} \in X$ such that $g\left(x_{1}\right)=F\left(x_{0}, y_{0}\right)$ and $g\left(y_{1}\right)=F\left(y_{0}, x_{0}\right)$. Again, using the assumption $F(X \times X) \subseteq g(X)$, choose $x_{2}, y_{2} \in X$ such that $g\left(x_{2}\right)=F\left(x_{1}, y_{1}\right)$ and $g\left(y_{2}\right)=$ $F\left(y_{1}, x_{1}\right)$. Continuing this process, we can construct two sequences $\left(x_{n}\right)$ and $\left(y_{n}\right)$ in $X$ as follows:

$$
g\left(x_{n+1}\right)=F\left(x_{n}, y_{n}\right) \quad \text { and } \quad g\left(y_{n+1}\right)=F\left(y_{n}, x_{n}\right)
$$

for all $n \geq 0$. We have to show that

$$
g\left(x_{n}\right) \leq g\left(x_{n+1}\right) \quad \text { and } \quad g\left(y_{n}\right) \geq g\left(y_{n+1}\right)
$$

for all $n \geq 0$. Since $g\left(x_{0}\right) \leq F\left(x_{0}, y_{0}\right)$ and $g\left(y_{0}\right) \geq F\left(y_{0}, x_{0}\right)$ and as $g\left(x_{1}\right)=F\left(x_{0}, y_{0}\right)$ and $g\left(y_{1}\right)=$ $F\left(y_{0}, x_{0}\right)$, we have $g\left(x_{0}\right) \leq g\left(x_{1}\right)$ and $g\left(y_{0}\right) \geq g\left(y_{1}\right)$. This proves that (3.7) and (3.8) hold for $n=0$. Let us suppose that (3.7) and (3.8) hold for some fixed $n>0$. Since $g\left(x_{n}\right) \leq g\left(x_{n+1}\right)$ and $g\left(y_{n}\right) \geq g y_{n+1}$, so by the mixed $g$-monotone property of $F$, we have

$$
g\left(x_{n+1}\right)=F\left(x_{n}, y_{n}\right) \leq F\left(x_{n+1}, y_{n}\right) \quad \text { and } \quad F\left(y_{n+1}, x_{n}\right) \leq F\left(y_{n}, x_{n}\right)=g\left(y_{n+1}\right) .
$$

Also,

$$
g\left(x_{n+2}\right)=F\left(x_{n+1}, y_{n+1}\right) \geq F\left(x_{n+1}, y_{n}\right) \quad \text { and } \quad F\left(y_{n+1}, x_{n}\right) \geq F\left(y_{n+1}, x_{n+1}\right)=g\left(y_{n+2}\right) .
$$


It follows that

$$
g\left(x_{n+1}\right) \leq g\left(x_{n+2}\right) \quad \text { and } \quad g\left(y_{n+1}\right) \geq g\left(y_{n+2}\right) \text {. }
$$

Thus, by the mathematical induction, we conclude that (3.7) and (3.8) hold for all $n \geq 0$.

Substituting $x=x_{n-1}, y=y_{n-1}, u=x_{n}$ and $v=y_{n}$ in (3.6), we obtain

$$
\begin{aligned}
& G\left(F\left(x_{n-1}, y_{n-1}\right), F\left(x_{n-1}, y_{n-1}\right), F\left(x_{n}, y_{n}\right), \phi(t)\right) \\
& \quad \geq G\left(g\left(x_{n-1}\right), g\left(x_{n-1}\right), g\left(x_{n}\right), t\right) * G\left(g\left(x_{n-1}\right), g\left(x_{n-1}\right), F\left(x_{n-1}, y_{n-1}\right), t\right) \\
& \quad * G\left(g\left(x_{n}\right), g\left(x_{n}\right), F\left(x_{n}, y_{n}\right), t\right)
\end{aligned}
$$

and

$$
\begin{aligned}
& H\left(F\left(x_{n-1}, y_{n-1}\right), F\left(x_{n-1}, y_{n-1}\right), F\left(x_{n}, y_{n}\right), \phi(t)\right) \\
& \quad \leq H\left(g\left(x_{n-1}\right), g\left(x_{n-1}\right), g\left(x_{n}\right), t\right) \diamond H\left(g\left(x_{n-1}\right), g\left(x_{n-1}\right), F\left(x_{n-1}, y_{n-1}\right), t\right) \\
& \quad \diamond H\left(g\left(x_{n}\right), g\left(x_{n}\right), F\left(x_{n}, y_{n}\right), t\right)
\end{aligned}
$$

for all $t>0$. Using (3.7) in the above inequalities, we get

$$
\begin{aligned}
G\left(g\left(x_{n}\right), g\left(x_{n}\right), g\left(x_{n+1}\right), \phi(t)\right) \geq & G\left(g\left(x_{n-1}\right), g\left(x_{n-1}\right), g\left(x_{n}\right), t\right) * G\left(g\left(x_{n-1}\right), g\left(x_{n-1}\right), g\left(x_{n}\right), t\right) \\
& * G\left(g\left(x_{n}\right), g\left(x_{n}\right), g\left(x_{n+1}\right), t\right) \\
= & G\left(g\left(x_{n-1}\right), g\left(x_{n-1}\right), g\left(x_{n}\right), t\right) * G\left(g\left(x_{n}\right), g\left(x_{n}\right), g\left(x_{n+1}\right), t\right)
\end{aligned}
$$

and

$$
\begin{aligned}
H\left(g\left(x_{n}\right), g\left(x_{n}\right), g\left(x_{n+1}\right), \phi(t)\right) \leq & H\left(g\left(x_{n-1}\right), g\left(x_{n-1}\right), g\left(x_{n}\right), t\right) \diamond H\left(g\left(x_{n-1}\right), g\left(x_{n-1}\right), g\left(x_{n}\right), t\right) \\
& \diamond H\left(g\left(x_{n}\right), g\left(x_{n}\right), g\left(x_{n+1}\right), t\right) \\
= & H\left(g\left(x_{n-1}\right), g\left(x_{n-1}\right), g\left(x_{n}\right), t\right) \diamond H\left(g\left(x_{n}\right), g\left(x_{n}\right), g\left(x_{n+1}\right), t\right)
\end{aligned}
$$

for all $t>0$. Hence, by Lemma 3.3, $\left(g\left(x_{n}\right)\right)$ is a Cauchy sequence with respect to the intuitionistic generalized fuzzy metric $(G, H)$. Again, by substituting $x=y_{n}, y=x_{n}, u=y_{n-1}$, and $v=x_{n-1}$ in (3.6), we get

$$
\begin{aligned}
& G\left(F\left(y_{n-1}, x_{n-1}\right), F\left(y_{n-1}, x_{n-1}\right), F\left(y_{n}, x_{n}\right), \phi(t)\right) \\
& \quad \geq G\left(g\left(y_{n-1}\right), g\left(y_{n-1}\right), g\left(y_{n}\right), t\right) * G\left(g\left(y_{n-1}\right), g\left(y_{n-1}\right), F\left(y_{n-1}, x_{n-1}\right), t\right) \\
& \quad * G\left(g\left(y_{n}\right), g\left(y_{n}\right), F\left(y_{n}, x_{n}\right), t\right)
\end{aligned}
$$

and, similarly,

$$
\begin{aligned}
& H\left(F\left(y_{n-1}, x_{n-1}\right), F\left(y_{n-1}, x_{n-1}\right), F\left(y_{n}, x_{n}\right), \phi(t)\right) \\
& \quad \leq H\left(g\left(y_{n-1}\right), g\left(y_{n-1}\right), g\left(y_{n}\right), t\right) \diamond H\left(g\left(y_{n-1}\right), g\left(y_{n-1}\right), F\left(y_{n-1}, x_{n-1}\right), t\right) \\
& \quad \diamond H\left(g\left(y_{n}\right), g\left(y_{n}\right), F\left(y_{n}, x_{n}\right), t\right) .
\end{aligned}
$$


By using (3.7), the above inequalities become

$$
\begin{aligned}
G\left(g\left(y_{n}\right), g\left(y_{n}\right), g\left(y_{n+1}\right), \phi(t)\right) \geq & G\left(g\left(y_{n-1}\right), g\left(y_{n-1}\right), g\left(y_{n}\right), t\right) * G\left(g\left(y_{n-1}\right), g\left(y_{n-1}\right), g\left(y_{n}\right), t\right) \\
& * G\left(g\left(y_{n}\right), g\left(y_{n}\right), g\left(y_{n+1}\right), t\right) \\
= & G\left(g\left(y_{n-1}\right), g\left(y_{n-1}\right), g\left(y_{n}\right), t\right) * G\left(g\left(y_{n}\right), g\left(y_{n}\right), g\left(y_{n+1}\right), t\right)
\end{aligned}
$$

and

$$
\begin{aligned}
H\left(g\left(y_{n}\right), g\left(y_{n}\right), g\left(y_{n+1}\right), \phi(t)\right) \leq & H\left(y_{n-1}, y_{n-1}, y_{n}, t\right) \diamond H\left(g\left(y_{n-1}\right), g\left(y_{n-1}\right), g\left(y_{n}\right), t\right) \\
& \diamond H\left(g\left(y_{n}\right), g\left(y_{n}\right), g\left(y_{n+1}\right), t\right) \\
= & H\left(g\left(y_{n-1}\right), g\left(y_{n-1}\right), g\left(y_{n}\right), t\right) \diamond H\left(g\left(y_{n}\right), g\left(y_{n}\right), g\left(y_{n+1}\right), t\right)
\end{aligned}
$$

for all $t>0$. This proves that $\left(g\left(y_{n}\right)\right)$ is a Cauchy sequence with respect to $(G, H)$. That is, $\left(g\left(x_{n}\right)\right)$ and $\left(g\left(y_{n}\right)\right)$ are Cauchy sequences with respect to $(G, H)$. Since $(X, G, H, *, \diamond)$ is a complete IGFM-space, there exist $x, y \in X$ such that

$$
(G, H)-\lim _{n \rightarrow \infty} g\left(x_{n}\right)=x \quad \text { and } \quad(G, H)-\lim _{n \rightarrow \infty} g\left(y_{n}\right)=y
$$

Therefore

$$
\left.\begin{array}{l}
(G, H)-\lim _{n \rightarrow \infty} g\left(x_{n}\right)=(G, H)-\lim _{n \rightarrow \infty} F\left(x_{n}, y_{n}\right)=x \quad \text { and } \\
(G, H)-\lim _{n \rightarrow \infty} g\left(y_{n}\right)=(G, H)-\lim _{n \rightarrow \infty} F\left(y_{n}, x_{n}\right)=y .
\end{array}\right\}
$$

Since $(g, F)$ is a compatible pair with respect to $(G, H)$, we have

$$
\left.\begin{array}{l}
\left.\lim _{n \rightarrow \infty} G\left(g\left(F\left(x_{n}, y_{n}\right)\right), g\left(F\left(x_{n}, y_{n}\right)\right), F\left(g\left(x_{n}\right), g\left(y_{n}\right)\right)\right), t\right)=1, \\
\left.\lim _{n \rightarrow \infty} H\left(g\left(F\left(x_{n}, y_{n}\right)\right), g\left(F\left(x_{n}, y_{n}\right)\right), F\left(g\left(x_{n}\right), g\left(y_{n}\right)\right)\right), t\right)=0, \\
\lim _{n \rightarrow \infty} G\left(g\left(F\left(y_{n}, x_{n}\right)\right), g\left(F\left(y_{n}, x_{n}\right)\right), F\left(g\left(y_{n}\right), g\left(x_{n}\right)\right), t\right)=1, \\
\lim _{n \rightarrow \infty} H\left(g\left(F\left(y_{n}, x_{n}\right)\right), g\left(F\left(y_{n}, x_{n}\right)\right), F\left(g\left(y_{n}\right), g\left(x_{n}\right)\right), t\right)=0
\end{array}\right\}
$$

for all $t>0$. Now, suppose that assumption (a) holds. From (3.10) and (3.11), by using the continuity of $F$ and $g$, we have

$$
G(g(x), g(x), F(x, y), t)=1 \quad \text { and } \quad H(g(x), g(x), F(x, y), t)=0
$$

for all $t>0$. Similarly, for all $t>0$, we get

$$
G(g(y), g(y), F(y, x), t)=1 \quad \text { and } \quad H(g(y), g(y), F(y, x), t)=0 \text {. }
$$

From (3.12) and (3.13), we obtain $g(x)=F(x, y)$ and $g(y)=F(y, x)$. This proves that $F$ and $g$ have a coupled coincidence point with respect to the intuitionistic generalized fuzzy metric $(G, H)$.

Lastly, let us assume that (b) holds. Since $\left(g\left(x_{n}\right)\right)$ is a non-decreasing sequence and $g\left(x_{n}\right)$ is convergent to $x$ with respect to the intuitionistic generalized fuzzy metric $(G, H)$, and also $\left(g\left(y_{n}\right)\right)$ is a non-increasing sequence and $g\left(y_{n}\right)$ is convergent to $y$ with respect to $(G, H)$, 
by our assumption we have $g\left(x_{n}\right) \leq x$ and $g\left(y_{n}\right) \geq y$ for all $n$. Since $(g, F)$ is a compatible pair, using the continuity of $g$, we have

$$
\begin{aligned}
g(x) & =(G, H)-\lim _{n \rightarrow \infty} g\left(g\left(x_{n}\right)\right)=(G, H)-\lim _{n \rightarrow \infty} g\left(F\left(x_{n}, y_{n}\right)\right) \\
& =(G, H)-\lim _{n \rightarrow \infty} F\left(g\left(x_{n}\right), g\left(y_{n}\right)\right)
\end{aligned}
$$

and

$$
\begin{aligned}
g(y) & =(G, H)-\lim _{n \rightarrow \infty} g\left(g\left(y_{n}\right)\right)=(G, H)-\lim _{n \rightarrow \infty} g\left(F\left(y_{n}, x_{n}\right)\right) \\
& =(G, H)-\lim _{n \rightarrow \infty} F\left(g\left(y_{n}\right), g\left(x_{n}\right)\right) .
\end{aligned}
$$

Write

$$
\begin{aligned}
G(g(x), g(x), F(x, y), \phi(t)) \geq & G\left(g(x), g(x), g\left(g\left(x_{n+1}\right)\right), \phi(t)-\phi(k t)\right) \\
& * G\left(g\left(g\left(x_{n+1}\right)\right), g\left(g\left(x_{n+1}\right)\right), F(x, y), \phi(k t)\right)
\end{aligned}
$$

and

$$
\begin{aligned}
H(g(x), g(x), F(x, y), \phi(t)) \leq & H\left(g(x), g(x), g\left(g\left(x_{n+1}\right)\right), \phi(t)-\phi(k t)\right) \\
& \diamond H\left(g\left(g\left(x_{n+1}\right)\right), g\left(g\left(x_{n+1}\right)\right), F(x, y), \phi(k t)\right)
\end{aligned}
$$

for all $k$ and $t>0$. Taking limit as $n \rightarrow \infty$, using the fact that $G$ is continuous and from the definition of IGFM-space, we have

$$
\left.\begin{array}{l}
G(x, x, F(x, y), \phi(t)) \geq \lim _{n \rightarrow \infty} G\left(g\left(g\left(x_{n+1}\right)\right), g\left(g\left(x_{n+1}\right)\right), F(x, y), \phi(k t)\right) \quad \text { and } \\
H(x, x, F(x, y), \phi(t)) \leq \lim _{n \rightarrow \infty} H\left(g\left(g\left(x_{n+1}\right)\right), g\left(g\left(x_{n+1}\right)\right), F(x, y), \phi(k t)\right)
\end{array}\right\}
$$

for all $t>0$. Since $g\left(x_{n+1}\right)=F\left(x_{n}, y_{n}\right)$ and $g\left(y_{n+1}\right)=F\left(y_{n}, x_{n}\right)$, using equalities (3.14) and (3.15) in (3.16), we get

$$
\begin{aligned}
& G(g(x), g(x), F(x, y), \phi(t)) \\
& \quad \geq \lim _{n \rightarrow \infty} G\left(g\left(F\left(x_{n}, y_{n}\right)\right), g\left(F\left(x_{n}, y_{n}\right)\right), F(x, y), \phi(k t)\right) \\
& \quad=\lim _{n \rightarrow \infty} G\left(F\left(g\left(x_{n}\right), g\left(y_{n}\right)\right), F\left(g\left(x_{n}\right), g\left(y_{n}\right)\right), F(x, y), \phi(k t)\right) \\
& \text { and } \\
& \quad \quad \begin{array}{l}
H(g(x), g(x), F(x, y), \phi(t)) \\
\quad \leq \lim _{n \rightarrow \infty} H\left(g\left(F\left(x_{n}, y_{n}\right)\right), g\left(F\left(x_{n}, y_{n}\right)\right), F(x, y), \phi(k t)\right) \\
\quad=\lim _{n \rightarrow \infty} H\left(F\left(g\left(x_{n}\right), g\left(y_{n}\right)\right), F\left(g\left(x_{n}\right), g\left(y_{n}\right)\right), F(x, y), \phi(k t)\right) .
\end{array}
\end{aligned}
$$

Using (3.6) in the right-hand side of (3.17) and then from (3.14) and (3.15), we obtain

$$
\begin{aligned}
& G(g(x), g(x), F(x, y), \phi(t)) \\
& \quad \geq \lim _{n \rightarrow \infty}\left\{G\left(g\left(g\left(x_{n}\right)\right), g\left(g\left(x_{n}\right)\right), g(x), k t\right) * G\left(g\left(g\left(x_{n}\right)\right), g\left(g\left(x_{n}\right)\right), F\left(g\left(x_{n}\right), g\left(y_{n}\right)\right), k t\right)\right. \\
& \quad * G(g(x), g(x), F(x, y), k t)\}
\end{aligned}
$$




$$
\begin{aligned}
& =G(g(x), g(x), g(x), k t) * G(g(x), g(x), F(x, y), k t) * G(g(x), g(x), F(x, y), k t) \\
& =G(g(x), g(x), F(x, y), k t)
\end{aligned}
$$

and, similarly, we have

$$
\begin{aligned}
& H(g(x), g(x), F(x, y), \phi(t)) \\
& \quad \leq \lim _{n \rightarrow \infty}\left\{H\left(g\left(g\left(x_{n}\right)\right), g\left(g\left(x_{n}\right)\right), g(x), k t\right) \diamond H\left(g\left(g\left(x_{n}\right)\right), g\left(g\left(x_{n}\right)\right), F\left(g\left(x_{n}\right), g\left(y_{n}\right)\right), k t\right)\right. \\
& \quad \diamond H(g(x), g(x), F(x, y), k t)\} \\
& =H(g(x), g(x), F(x, y), k t) .
\end{aligned}
$$

Letting $k \rightarrow \infty$ in the last two inequalities, we get

$$
G(g(x), g(x), F(x, y), \phi(t))=1 \quad \text { and } \quad H(g(x), g(x), F(x, y), \phi(t))=0
$$

for all $t>0$. From the definition of IGFM-space, we conclude that $g(x)=F(x, y)$ and $g(y)=$ $F(y, x)$ and hence $F$ and $g$ have a coupled coincidence point in $X$.

Corollary 3.5 Let $(X, \leq)$ be a partially ordered set and $(X, G, H, *, \diamond)$ be a complete IGFMspace. Suppose that $F: X \times X \rightarrow X$ is a mapping having the mixed monotone property such that there exist $x_{0}, y_{0} \in X$ with $x_{0} \leq F\left(x_{0}, y_{0}\right)$ and $y_{0} \geq F\left(y_{0}, x_{0}\right)$. Suppose that there exists $\phi \in \Phi$ such that

$$
\left.\begin{array}{l}
G(F(x, y), F(x, y), F(u, v), \phi(t)) \\
\quad \geq G(x, x, u, t) * G(x, x, F(x, y), t) * G(u, u, F(u, v), t) \quad \text { and } \\
H(F(x, y), F(x, y), F(u, v), \phi(t)) \\
\quad \leq H(x, x, u, t) \diamond H(x, x, F(x, y), t) \diamond H(u, u, F(u, v), t)
\end{array}\right\}
$$

for all $x, y, u, v \in X$ and $t>0$, for which $x \leq u$ and $y \geq v$, or $x \geq u$ and $y \leq v$. Also, suppose that either

(a) $F$ is continuous, or

(b) $X$ has the following property:

(i) if a non-decreasing sequence $x_{n}$ is convergent to $x$ with respect to $(G, H)$, then $x_{n} \leq x$ for all $n$,

(ii) if a non-increasing sequence $y_{n}$ is convergent to $y$ with respect to $(G, H)$, then $y_{n} \geq y$ for all $n$.

Then there exist $x, y \in X$ such that $x=F(x, y)$ and $y=F(y, x)$, that is, $F$ has a coupled fixed point in $X$.

Proof The proof follows by putting $g=I$, the identity mapping, in Theorem 3.4.

We consider the following example in support of our Theorem 3.4.

Example 3.6 Let $(X, \leq)$ be a partially ordered set with $X=[0,1]$. Suppose that $a * b=$ $\min \{a, b\}$ and $a \diamond b=\max (a, b)$. Consider $G, H$ to be fuzzy sets on $X^{3} \times(0, \infty)$ defined 
by

$$
\begin{aligned}
& G(x, y, z, t)=\frac{t}{t+|x-y|+|y-z|+|z-x|} \quad \text { and } \\
& H(x, y, z, t)=\frac{|x-y|+|y-z|+|z-x|}{t+|x-y|+|y-z|+|z-x|}
\end{aligned}
$$

for all $x, y, z \in X$ and $t>0$. Then $(X, G, H, *, \diamond)$ is a complete IGFM-space. Let the mapping $g: X \rightarrow X$ be defined by

$$
g(x)=x^{2} \quad \text { for all } x \in X
$$

and let the mapping $F: X \times X \rightarrow X$ be defined by

$$
F(x, y)= \begin{cases}\frac{x^{2}-y^{2}}{3} & \text { if } x \geq y, \\ 0 & \text { if } x<y\end{cases}
$$

for all $x, y \in X$. Then $F$ satisfies the mixed $g$-monotone property $F$. Let $\phi(t): \mathbb{R}^{+} \rightarrow \mathbb{R}^{+}$be such that $\phi(t)=\frac{2}{3} t$ for all $t \in \mathbb{R}^{+}$. Suppose that $\left(x_{n}\right)$ and $\left(y_{n}\right)$ are two sequences in $X$ such that

$$
\lim _{n \rightarrow \infty} F\left(x_{n}, y_{n}\right)=a, \quad \lim _{n \rightarrow \infty} g\left(x_{n}\right)=a \quad \text { and } \quad \lim _{n \rightarrow \infty} F\left(y_{n}, x_{n}\right)=b, \quad \lim _{n \rightarrow \infty} g\left(y_{n}\right)=b .
$$

Then $a=0$ and $b=0$. For all $n \geq 0$, we define

$$
\begin{aligned}
& g\left(x_{n}\right)=x_{n}^{2}, \quad g\left(y_{n}\right)=y_{n}^{2}, \\
& F\left(x_{n}, y_{n}\right)= \begin{cases}\frac{x_{n}^{2}-y_{n}^{2}}{3} & \text { if } x_{n} \geq y_{n}, \\
0 & \text { if } x_{n}<y_{n},\end{cases}
\end{aligned}
$$

and

$$
F\left(y_{n}, x_{n}\right)= \begin{cases}\frac{y_{n}^{2}-x_{n}^{2}}{3} & \text { if } y_{n} \geq x_{n} \\ 0 & \text { if } y_{n}<x_{n}\end{cases}
$$

From the above, we see that

$$
\begin{aligned}
& G\left(g\left(F\left(x_{n}, y_{n}\right)\right), g\left(F\left(x_{n}, y_{n}\right)\right), F\left(g\left(x_{n}\right), g\left(y_{n}\right)\right), t\right) \rightarrow 1 \quad \text { as } n \rightarrow \infty, \\
& H\left(g\left(F\left(x_{n}, y_{n}\right)\right), g\left(F\left(x_{n}, y_{n}\right)\right), F\left(g\left(x_{n}\right), g\left(y_{n}\right)\right), t\right) \rightarrow 0 \quad \text { as } n \rightarrow \infty,
\end{aligned}
$$

and

$$
\begin{aligned}
& G\left(g\left(F\left(y_{n}, x_{n}\right)\right), g\left(F\left(y_{n}, x_{n}\right)\right), F\left(g\left(y_{n}\right), g\left(x_{n}\right)\right), t\right) \rightarrow 1 \quad \text { as } n \rightarrow \infty, \\
& H\left(g\left(F\left(y_{n}, x_{n}\right)\right), g\left(F\left(y_{n}, x_{n}\right)\right), F\left(g\left(y_{n}\right), g\left(x_{n}\right)\right), t\right) \rightarrow 0 \quad \text { as } n \rightarrow \infty .
\end{aligned}
$$


This proves that $F$ and $g$ are compatible with respect to $(G, H)$. Also, suppose that $x_{0}=0$ and $y_{0}=\alpha$ are two points in $X$ such that

$$
g\left(x_{0}\right)=g(0)=F(0, \alpha)=F\left(x_{0}, y_{0}\right)
$$

and

$$
g\left(y_{0}\right)=g(\alpha)=\alpha^{2} \geq \frac{\alpha^{2}}{3}=F(\alpha, 0)=F\left(y_{0}, x_{0}\right) .
$$

Now it is left to show that (3.6) of Theorem 3.4 is satisfied with $\phi(t)=\frac{2}{3} t$ as defined above. Let $x, y, u, v \in X$ be such that $g(x) \leq g(u)$ and $g(y) \geq g(v)$, that is, $x^{2} \leq u^{2}, y^{2} \geq v^{2}$. We have the following possible cases.

Case 1: When $x \geq y$ and $u \geq v$. Then we get

$$
\begin{aligned}
G & (F(x, y), F(x, y), F(u, v), \phi(t)) \\
& =G\left(\frac{x^{2}-y^{2}}{3}, \frac{x^{2}-y^{2}}{3}, \frac{u^{2}-v^{2}}{3}, \frac{2}{3} t\right) \\
& =\frac{\frac{2}{3} t}{\frac{2}{3} t+2\left|\frac{\left(x^{2}-u^{2}\right)-\left(y^{2}-v^{2}\right)}{3}\right|} \\
& =\frac{t}{t+\left|\left(x^{2}-u^{2}\right)-\left(y^{2}-v^{2}\right)\right|} \\
& \geq \frac{t}{t+2\left|u^{2}-\frac{u^{2}-v^{2}}{3}\right|} \\
& =G(g(u), g(u), F(u, v), t) \\
& \geq G(g(x), g(x), g(u), t) * G(g(x), g(x), F(x, y), t) * G(g(u), g(u), F(u, v), t)
\end{aligned}
$$

and

$$
\begin{aligned}
H & (F(x, y), F(x, y), F(u, v), \phi(t)) \\
& =H\left(\frac{x^{2}-y^{2}}{3}, \frac{x^{2}-y^{2}}{3}, \frac{u^{2}-v^{2}}{3}, \frac{2}{3} t\right) \\
& =\frac{2\left|\frac{\left(x^{2}-u^{2}\right)-\left(y^{2}-v^{2}\right)}{3}\right|}{\frac{2}{3} t+2\left|\frac{\left(x^{2}-u^{2}\right)-\left(y^{2}-v^{2}\right)}{3}\right|} \\
& =\frac{\left|\left(x^{2}-u^{2}\right)-\left(y^{2}-v^{2}\right)\right|}{t+\left|\left(x^{2}-u^{2}\right)-\left(y^{2}-v^{2}\right)\right|} \\
& \leq \frac{2\left|u^{2}-\frac{u^{2}-v^{2}}{3}\right|}{t+2\left|u^{2}-\frac{u^{2}-v^{2}}{3}\right|} \\
& =H(g(u), g(u), F(u, v), t) \\
& \leq H(g(x), g(x), g(u), t) \diamond H(g(x), g(x), F(x, y), t) \diamond H(g(u), g(u), F(u, v), t) .
\end{aligned}
$$

Case 2: If $x \geq y, u<v$, then we see that this assumption cannot happen since $x \leq u$. 
Case 3: When $x<y$ and $u \geq v$. Then

$$
\begin{aligned}
& G(F(x, y), F(x, y), F(u, v), \phi(t)) \\
& \quad=G\left(0,0, \frac{u^{2}-v^{2}}{3}, \frac{2}{3} t\right) \\
& \quad=\frac{\frac{2}{3} t}{\frac{2}{3} t+2\left|\frac{\left(u^{2}-v^{2}\right)}{3}\right|} \\
& \quad=\frac{t}{t+\left|u^{2}-v^{2}\right|} \\
& \quad \geq \frac{t}{t+2\left|u^{2}-x^{2}\right|} \\
& \quad=G(g(x), g(x), g(u), t) \\
& \quad \geq G(g(x), g(x), g(u), t) * G(g(x), g(x), F(x, y), t) * G(g(u), g(u), F(u, v), t)
\end{aligned}
$$

and

$$
\begin{aligned}
H & (F(x, y), F(x, y), F(u, v), \phi(t)) \\
& =H\left(0,0, \frac{u^{2}-v^{2}}{3}, \frac{2}{3} t\right) \\
& =\frac{2\left|\frac{\left(u^{2}-v^{2}\right)}{3}\right|}{\frac{2}{3} t+2\left|\frac{\left(u^{2}-v^{2}\right)}{3}\right|} \\
& =\frac{\left|u^{2}-v^{2}\right|}{t+\left|u^{2}-v^{2}\right|} \\
& \leq \frac{2\left|u^{2}-x^{2}\right|}{t+2\left|u^{2}-x^{2}\right|} \\
& =H(g(x), g(x), g(u), t) \\
& \leq H(g(x), g(x), g(u), t) \diamond H(g(x), g(x), F(x, y), t) \diamond H(g(u), g(u), F(u, v), t) .
\end{aligned}
$$

Case 4. If $x<y$ and $u<v$, then both $F(x, y)=0$ and $F(u, v)=0$. Therefore

$$
G(F(x, y), F(x, y), F(u, v), \phi(t))=1 \quad \text { and } \quad H(F(x, y), F(x, y), F(u, v), \phi(t))=0 .
$$

Obviously, assumption (3.6) is fulfilled.

Thus all the hypotheses of Theorem 3.4 are fulfilled. So, we conclude that $F$ and $g$ have a coupled coincidence point. In this case, $(0,0)$ is a coupled coincidence point of $F$ and $g$ in $X$.

Remark 3.7 Proceeding along the same technique as given by Sintunavarat et al. [16], we can also obtain our coupled coincidence point theorem without using the commutative condition. 


\section{Competing interests}

The authors declare that they have no competing interests.

\section{Authors' contributions}

The authors contributed equally and significantly in writing this paper. Both authors read and approved the final manuscript.

\section{Acknowledgements}

The authors gratefully acknowledge the financial support from King Abdulaziz University, Jeddah, Saudi Arabia.

\section{Received: 26 February 2013 Accepted: 26 September 2013 Published: 07 Nov 2013}

\section{References}

1. Zadeh, LA: Fuzzy sets. Inf. Control 8, 338-353 (1965)

2. Erceg, MA: Metric spaces in fuzzy set theory. J. Math. Anal. Appl. 69, 205-230 (1979)

3. Kaleva, O, Seikkala, S: On fuzzy metric spaces. Fuzzy Sets Syst. 12, 215-229 (1984)

4. Kramosil, O, Michalek, J: Fuzzy metric and statistical metric spaces. Kybernetika 11, 326-334 (1975)

5. George, A, Veeramani, P: On some results in fuzzy metric spaces. Fuzzy Sets Syst. 64, 395-399 (1994)

6. Atanassov, K: Intuitionistic fuzzy sets, VII ITKR's Session, Sofia, June 1983 (Deposed in Central Science-Technical Library of Bulg. Academy of Science, 1697/84) (in Bulgarian)

7. Park, JH: Intuitionistic fuzzy metric spaces. Chaos Solitons Fractals 22, 1039-1046 (2004)

8. Al-Fhaid, AS, Mohiuddine, SA: On the Ulam stability of mixed type QA mappings in IFN-spaces. Adv. Differ. Equ. 2013, 203 (2013)

9. Saadati, R, Park, JH: On the intuitionistic fuzzy topological spaces. Chaos Solitons Fractals 27, 331-344 (2006)

10. Mohiuddine, SA: Stability of Jensen functional equation in intuitionistic fuzzy normed space. Chaos Solitons Fractals 42, 2989-2996 (2009)

11. Mohiuddine, SA, Alotaibi, A, Obaid, M: Stability of various functional equations in non-Archimedean intuitionistic fuzzy normed spaces. Discrete Dyn. Nat. Soc. 2012, Article ID 234727 (2012)

12. Mohiuddine, SA, Şevli, H: Stability of Pexiderized quadratic functional equation in intuitionistic fuzzy normed space. J. Comput. Appl. Math. 235, 2137-2146 (2011)

13. Mursaleen, $M$, Ansari, KJ: Stability results in intuitionistic fuzzy normed spaces for a cubic functional equation. Appl. Math. Inform. Sci. 7(5), 1685-1692 (2013)

14. Mursaleen, M, Mohiuddine, SA: On stability of a cubic functional equation in intuitionistic fuzzy normed spaces. Chaos Solitons Fractals 42, 2997-3005 (2009)

15. Mursaleen, M, Mohiuddine, SA: Nonlinear operators between intuitionistic fuzzy normed spaces and Fréhet differentiation. Chaos Solitons Fractals 42, 1010-1015 (2009)

16. Sintunavarat, W, Cho, YJ, Kumam, P: Coupled coincidence point theorems for contractions without commutative condition in intuitionistic fuzzy normed spaces. Fixed Point Theory Appl. 2011, 81 (2011)

17. Abbas, M, Ali, B, Sintunavarat, W, Kumam, P: Tripled fixed point and tripled coincidence point theorems in intuitionistic fuzzy normed spaces. Fixed Point Theory Appl. 2012, 187 (2012)

18. Sintunavarat, W, Kumam, P: Fixed point theorems for a generalized intuitionistic fuzzy contraction in intuitionistic fuzzy metric spaces. Thai J. Math. 10(1), 123-135 (2012)

19. Mohiuddine, SA, Cancan, M, Şevli, H: Intuitionistic fuzzy stability of a Jensen functional equation via fixed point technique. Math. Comput. Model. 54, 2403-2409 (2011)

20. Mohiuddine, SA, Alotaibi, A: Fuzzy stability of a cubic functional equation via fixed point technique. Adv. Differ. Equ. 2012, 48 (2012)

21. Mohiuddine, SA, Alghamdi, MA: Stability of functional equation obtained through a fixed-point alternative in intuitionistic fuzzy normed spaces. Adv. Differ. Equ. 2012, 141 (2012)

22. Mustafa, Z, Sims, B: A new approach to generalized metric spaces. J. Nonlinear Convex Anal. 7(2), $289-297$ (2006)

23. Mustafa, Z, Obiedat, H, Awawdeh, F: Some fixed point theorem for mapping on complete G-metric spaces. Fixed Point Theory Appl. 2008, Article ID 189870 (2008)

24. Mohiuddine, SA, Alotaibi, A: On coupled fixed point theorems for nonlinear contractions in partially ordered G-metric spaces. Abstr. Appl. Anal. 2012, Article ID 897198 (2012)

25. Mohiuddine, SA, Alotaibi, A: Some results on tripled fixed point for nonlinear contractions in partially ordered G-metric spaces. Fixed Point Theory Appl. 2012, 179 (2012)

26. Abbas, M, Sintunavarat, W, Kumam, P: Coupled fixed point in partially ordered G-metric spaces. Fixed Point Theory Appl. 2012, 31 (2012)

27. Aydi, H, Karapinar, E, Shatnawi, W: Tripled fixed point results in generalized metric spaces. J. Appl. Math. 2012, Article ID 314279 (2012)

28. Choudhury, BS, Maity, P: Coupled fixed point results in generalized metric spaces. Math. Comput. Model. 54, 73-79 (2011)

29. Karapinar, E, Kumam, P, Erhan, IM: Coupled fixed point theorems on partially ordered G-metric spaces. Fixed Point Theory Appl. 2012, 174 (2012)

30. Karapinar, E, Erhan, M, Ulus, AY: Cyclic contractions on G-metric spaces. Abstr. Appl. Anal. 2012, Article ID 182947 (2012)

31. Luong, NV, Thuan, NX: Coupled fixed point theorems in partially ordered G-metric spaces. Math. Comput. Model. 55, 1601-1609 (2012)

32. Shatanawi, W: Some fixed point theorems in ordered G-metric spaces and applications. Abstr. Appl. Anal. 2011, Article ID 126205 (2011)

33. Tahat, N, Aydi, H, Karapinar, E, Shatanawi, W: Common fixed points for single-valued and multi-valued maps satisfying a generalized contraction in G-metric spaces. Fixed Point Theory Appl. 2012, 48 (2012)

34. Sun, G, Yang, K: Generalized fuzzy metric spaces with properties. Res. J. Appl. Sci. 2, 673-678 (2010) 
35. Rao, KPR, Altun, I, Bindu, SH: Common coupled fixed-point theorems in generalized fuzzy metric spaces. Adv. Fuzzy Syst. 2011, Article ID 986748 (2011)

36. Hu, X-Qi, Luo, Q: Coupled coincidence point theorems for contractions in generalized fuzzy metric spaces. Fixed Point Theory Appl. 2012, 196 (2012)

37. Bhaskar, TG, Lakshmikantham, V: Fixed point theorems in partially ordered metric spaces and applications. Nonlinear Anal. 65, 1379-1393 (2006)

38. Lakshmikantham, V, Ćirić, L: Coupled fixed point theorems for nonlinear contractions in partially ordered metric spaces. Nonlinear Anal. 70, 4341-4349 (2009)

39. Agarwal, RP, El-Gebeily, MA, O’Regan, D: Generalized contractions in partially ordered metric spaces. Appl. Anal. 87, 109-116 (2008)

40. Aydi, H, Damjanović, B, Samet, B, Shatanawi, W: Coupled fixed point theorems for nonlinear contractions in partially ordered G-metric spaces. Math. Comput. Model. 54, 2443-2450 (2011)

41. Choudhury, BS, Kundu, A: A coupled coincidence point result in partially ordered metric spaces for compatible mappings. Nonlinear Anal. 73, 2524-2531 (2010)

42. Mursaleen, M, Mohiuddine, SA, Agarwal, RP: Coupled fixed point theorems for $\alpha-\psi$-contractive type mappings in partially ordered metric spaces. Fixed Point Theory Appl. 2012, 228 (2012) (Corrigendum to 'Coupled fixed point theorems for $\alpha$ - $\psi$-contractive type mappings in partially ordered metric spaces.' Fixed Point Theory Appl. 2013,127 (2013))

43. Nieto, JJ, Rodríguez-López, R: Contractive mapping theorems in partially ordered sets and applications to ordinary differential equations. Order 22, 223-239 (2005)

44. Nieto, JJ, Rodriguez-López, R: Existence and uniqueness of fixed point in partially ordered sets and applications to ordinary differential equations. Acta Math. Sin. Engl. Ser. 23(12), 2205-2212 (2007)

45. Ran, ACM, Reurings, MCB: A fixed point theorem in partially ordered sets and some applications to matrix equations. Proc. Am. Math. Soc. 132, 1435-1443 (2004)

46. Sintunavarat, W, Cho, YJ, Kumam, P: Coupled fixed point theorems for weak contraction mapping under F-invariant set. Abstr. Appl. Anal. 2012, Article ID 324874 (2012)

47. Sintunavarat, W, Petruşel, A, Kumam, P: Common coupled fixed point theorems for $W^{*}$-compatible mappings without mixed monotone property. Rend. Circ. Mat. Palermo 61, 361-383 (2012)

48. Sintunavarat, W, Kumam, P, Cho, YJ: Coupled fixed point theorems for nonlinear contractions without mixed monotone property. Fixed Point Theory Appl. 2012, 170 (2012)

49. Hu, XQ: Common coupled fixed point theorems for contractive mappings in fuzzy metric spaces. Fixed Point Theory Appl. 2011, Article ID 363716 (2011)

50. Schweizer, B, Sklar, A: Statistical metric spaces. Pac. J. Math. 10, 314-334 (1960)

10.1186/1687-1812-2013-265

Cite this article as: Mohiuddine and Alotaibi: Coupled coincidence point theorems for compatible mappings in partially ordered intuitionistic generalized fuzzy metric spaces. Fixed Point Theory and Applications 2013, 2013:265

\section{Submit your manuscript to a SpringerOpen ${ }^{\circ}$ journal and benefit from:}

- Convenient online submission

Rigorous peer review

- Immediate publication on acceptance

- Open access: articles freely available online

- High visibility within the field

- Retaining the copyright to your article 